\title{
Robots, labor markets, and universal basic income
}

\author{
Antonio Cabrales ${ }^{1,2}$, Penélope Hernández ${ }^{2,3}$ \& Angel Sánchez (iD) 2,4,5,6凶
}

\begin{abstract}
Automation is a big concern in modern societies in view of its widespread impact on many socioeconomic issues including income, jobs, and productivity. While previous studies have concentrated on determining the effects on jobs and salaries, our aim is to understand how automation affects productivity, and how some policies, such as taxes on robots or universal basic income, moderate or aggravate those effects. To this end, we have designed an experiment where workers make productive effort decisions, and managers can choose between workers and robots to do these tasks. In our baseline treatment, we measure the effort made by workers who may be replaced by robots, and also elicit firm replacement decisions. Subsequently, we carry out treatments in which workers have a universal basic income of about a fifth of the workers' median wages, or where there is a tax levy on firms who replace workers by robots. We complete the picture of the impact of automation by looking into the coexistence of workers and robots with part-time jobs. We find that the threat of a robot substitution does not affect the amount of effort exerted by workers. Also, neither universal basic income nor a tax on robots decrease workers' effort. We observe that the robot substitution tax reduces the probability of worker substitution. Finally, workers that benefit from managerial decisions to not substitute them by more productive robots do not increase their effort level. Our conclusions shed light on the interplay of policy and workers behavior under pervasive automation.
\end{abstract}

\footnotetext{
${ }^{1}$ Departamento de Economía, Universidad Carlos III de Madrid, 28903 Getafe, Spain. ${ }^{2}$ Unidad Mixta Interdisciplinar de Comportamiento y Complejidad Social (UMICCS), UC3M-UV-UZ, Getafe, Spain. ${ }^{3}$ LINEEX/Departament d'Economía, Universitat de València, València, Spain. ${ }^{4}$ GISC/Departamento de Matemáticas, Universidad Carlos III de Madrid, 28911 Leganés, Spain. ${ }^{5}$ Instituto de Biocomputación y Física de Sistemas Complejos, Universidad de Zaragoza, 50015 Zaragoza, Spain. ${ }^{6}$ UC3M Santander Institute for Big Data (IBiDat), Universidad Carlos III de Madrid, 28903 Getafe, Spain.

凶email: anxo@math.uc3m.es
} 


\section{Introduction}

he rapidly growing wave of automation is submitting our society to large changes of profound consequences. Undoubtedly, the availability of a cheaper, more efficient workforce of robots will affect every aspect of our socioeconomic life, from welfare to job opportunities and conditions through markets and businesses. In this context, there is a growing concern about optimal policy responses to the challenges associated with those social and economic effects. Indeed, there is an emerging research field on this topic showing the impacts of automation on society. For instance, Frey and Osborne (2013) estimate that $47 \%$ of current US jobs are at risk from automation. The World Bank (2016) also estimates that about $57 \%$ of current jobs in the whole OECD could be automated in the coming decades. On the other hand, Arntz et al. (2016) argue that these figures could be overestimated in so far as they do not take into account the fact that workers will specialize in hard-to-automate jobs; in that case, we would experience a lower, but still very relevant, loss of $9 \%$ of jobs within OECD countries. This and related research points to the sizable effects that automation may have on the job market.

A specially relevant question has been posed by Acemoglu and Restrepo (2017) who analyzed the impact of robots and automation on jobs and salaries. They estimate that for each extra robot per 1000 workers, jobs will decrease between $0.18 \%$ and $0.34 \%$ and salaries will also decrease between $0.25 \%$ and $0.5 \%$. Further, the study (Autor and Salomons, 2018) considered the impact of automation on employment and salaries with data from 19 developed countries over four decades. They find a net positive effect on employment, even if the direct effect on the affected sector is negative. On the other hand, the net effect on salaries is negative. For this reason, they argue that policies should concern themselves with the distributional aspects of technological change rather than with job losses.

These previous studies have concentrated on determining the effects on jobs and salaries. To shed light on the impact of automation from a complementary viewpoint, we here aim to understanding the effects of automation on productivity, and also to determining the effects of some proposed policies, such as taxes on robots or universal basic income, on productivity and on firms' decisions. Addressing these issues from a standard empirical methodology is not possible, as those policies have not been trialed in the field. Also, productivity is notoriously difficult to measure under standard field conditions because of lack of control. Therefore, we have designed an experiment in which workers make productive effort decisions, and managers can choose between workers and robots to do these tasks. In our baseline treatment, we measure the effort made by workers who may be replaced by robots who are on average more productive than themselves, and we also monitor firm replacement decisions. Once the baseline results are established, we look at how they change when workers can access a universal basic income of about a fifth of the workers' median wages, as in a pilot experiment in Finland (Kangas et al., 2019). We then go on to study the effect of taxes imposed on firms that replace a worker by a robot. In a last treatment, we consider a situation in which workers and robots coexist with the option of choosing to work part-time.

Our specifically designed experimental setup allows us to draw several conclusions that can be relevant for policy making on this issue. First, and contrary to what standard theoretical arguments would predict, the threat of a robot substitution does not affect the amount of effort exerted by workers. Second, neither universal basic income, nor the tax levied on firms when they replace a worker by a robot decrease workers' effort, again in contradiction with theoretical predictions. Third, the robot substitution tax does indeed reduce the probability of worker substitution in accordance with its intended goal. Interestingly, workers that are not substituted by a more productive robot do not increase their effort subsequently, as theories of reciprocal altruism would suggest. In light of these results, the issue on the impact of establishing universal income or robot taxes need further consideration both by researchers and policy makers.

\section{Experimental design and methods}

To address the issue of the impact of automation on productivity under different policies, we recruited 900 individuals to take part in an experiment with 9 treatments. The sample were 59\% female, and $98 \%$ university students. The mean age was 21 , with a minimum of 19 and a maximum of 30 . In our recruitment we tried to recruit students from diverse fields to be representative of future graduate labor markets. Instructions in Spanish, exactly as they were provided to the participants, and their translation into English, are provided in the Supporting Information.

The experiment was designed as follows: We begin by asking the participants to work on a set of tasks (counting letters in a text and adding up integer numbers, see SI) and as a result they receive a monetary payment as a function of their performance. Except in the control treatment, after this first stage participants may go to a second one or they may be substituted by a robot in a manner we discuss below. If they do proceed to the second stage, they perform a similar task and accumulate their corresponding payment, their earnings from the experiment being the sum of the money obtained in the two stages plus a show up fee. If they are substituted, they neither perform any task nor receive any payment from this second stage. In the control treatment, participants always proceed to the second stage. All this is made known to the participants from the beginning.

Preliminary pilots and the control treatments were used to obtain the effort distribution in the first task, from which random robots were sampled in the rest of the treatments as we discuss in the following. The replacement of robots by workers is done in two different forms, giving rise to two corresponding treatments: exogenous and endogenous. In the exogenous treatment, a robot is randomly selected to be compared with every worker. Robots are individually and randomly associated to each different individual. Then, the output of the participant is compared with that of its assigned robot, which is random but on average superior to that of an average participant (calibrated in pilots prior to the experiment, as well as with the control treatment). If the assigned robot has higher productivity than the participant, with probability $90 \%$ the latter is substituted and does not proceed to the second stage.

In the endogenous treatment, the participants are randomly classified as type $A$ or type $B$ independently of their performance in the first stage. Subjects of type $B$ play the role of employees and subjects of type $A$ play the role of managers. Each $A$ subject has several $B$ subjects of whom she is responsible. Before the second stage starts, $A$ subjects decide, knowing the production of each of the $B$ subjects she manages, and the productivity of a randomly assigned robot, if the subject is replaced or not. Managers also work during the second stage so participants in the lab can not identify who is a manager. A subjects earn the result of their own production plus an amount that is proportional to the production of their teams, while $B$ subjects only receive the earnings from their own effort. In addition to these treatments, both in the exogenous and endogenous condition we have a number of sessions in which all participants receive a universal basic income that is independent of their productivity. The value of the universal basic income used in the experiment is obtained dividing by 5 the median output in the control treatment. 
This computation follows the spirit of the pilot experiment in Finland where median salary is about 3000 euros a month and the amount of basic income in the experiment was about 600 euros (Kangas et al., 2019). Therefore, given that median output of subjects' work in the control treatment was 16.15 euros, we introduced a basic income of 3.4 euros in our experiment. For comparison, the median earnings of participants in our experiment were approximately 12 euros, so the basic income was a significant contribution when applicable, but not the main one. In the endogenous treatment, we also carried out sessions in which the replacement of a worker by a robot was subjected to a tax. Finally, another variant of the endogenous treatment allowed managers to offer workers in their team a part-time contract. Details of the implementation of the tax and on the part-time contract are included in the SI. The combination of all these treatments allows us to study the independent or combined effects of the different policies (tax, basic income, and part-time work) both when the replacement is endogenous and when it is exogenous (where that is relevant).

In summary, the nine treatments considered were the following ones:

- T0, Baseline (control group): 60 subjects.

- T1, Endogenous without basic income and no tax: 120 subjects.

- T2, Endogenous with basic income and no tax: 120 subjects.

- T3, Endogenous without basic income and tax: 120 subjects.

- T4, Endogenous with basic income and tax: 120 subjects.

- T5, Endogenous without tax and option to work part-time: 120 subjects.

- T6, Endogenous with tax and option to work part-time: 120 subjects.

- T7, Exogenous without basic income: 60 subjects.

- T8, Exogenous with basic income: 60 subjects.

The presentation of our design would be incomplete without a discussion of the limitations of our approach. Obviously, a lab experiment does not reproduce totally real life. At the lab we are making a stylised projection of the decision frame similar to the one that people should face in normal life. This process of abstraction allows to disentangle the significance of few variables instead and of a total representation of real decision; however, it can be argued that it is too far away from the real context to draw conclusions. However, the large body of literature on experimental economics has shown that the results from the lab do offer insights about human behavior in daily life contexts (Levitt and List, 2007). In any event, most of the information available on the issue of interest here comes from surveys which are even further separated from the respondent's actual situation. Another feature to take into account is about the monetary incentives that experimental subjects could take. While this amount may be regarded as small, it is typically calculated so average earnings are around 15 euros per hour of participation, so it is quite a fair payment for general participants. Finally, the amount of the sample might be a problem, but in our case we have 900 individuals which should be enough to detect the effects under scrutiny.

\section{Theoretical framework}

In order to provide a reference frame for our experiments, we begin by developing a theory of the experiment we have just described. To begin with, the total output of agent $i$ in period $j$ is a function of their idiosyncratic productivity $b_{i}$, and their effort in the period $e_{i j}$. We assume the money equivalent cost of effort is quadratic. The total income of an agent is output minus effort, and we also assume agents are risk averse, so their utility will be a concave function of income $U(\cdot)$. There is no discounting as there is virtually no time between periods in our experiment. In addition, we consider that the probability that an agent is not replaced by a robot in the second stage is a function of her output in the first one, $p\left(b_{i} e_{i 1}\right)$. With this, and including when present the amount of universal basic income, $B$, the total utility is

$$
U\left(b_{i} e_{i 1}-\frac{1}{2} e_{i 1}^{2}\right)+U\left(\left(b_{i} e_{i 2}-\frac{1}{2} e_{i 2}^{2}\right) p\left(b_{i} e_{i 1}\right)+B\right)
$$

The maximization of this utility as a function of the effort exerted in the first period, $e_{i 1}$, requires

$$
\begin{gathered}
U^{\prime}\left(b_{i} e_{i 1}-\frac{1}{2} e_{i 1}^{2}\right)\left(b_{i}-e_{i 1}\right) \\
+U^{\prime}\left(\left(b_{i} e_{i 2}-\frac{1}{2} e_{i 2}^{2}\right) p\left(b_{i} e_{i 1}\right)+B\right) p^{\prime}\left(b_{i} e_{i 1}\right) b_{i}=0
\end{gathered}
$$

which can be written compactly as

$$
F\left(e_{i 1}, B\right)=0
$$

This means that we can write

$$
\frac{\partial e_{i 1}(B)}{\partial B}=-\frac{F_{B}}{F_{e_{i 1}}}
$$

with

$$
\begin{aligned}
F_{B}= & U^{\prime \prime}\left(\left(b_{i} e_{i 2}-\frac{1}{2} e_{i 2}^{2}\right) p\left(b_{i} e_{i 1}\right)+B\right) p^{\prime}\left(b_{i} e_{i 1}\right) b_{i} \\
F_{e_{i 1}}= & U^{\prime \prime}\left(b_{i} e_{i 1}-\frac{1}{2} e_{i 1}^{2}\right)\left(b_{i}-e_{i 1}\right)^{2}-U^{\prime}\left(b_{i} e_{i 1}-\frac{1}{2} e_{i 1}^{2}\right) \\
& +U^{\prime \prime}\left(\left(b_{i} e_{i 2}-\frac{1}{2} e_{i 2}^{2}\right) p\left(b_{i} e_{i 1}\right)+B\right)\left(p^{\prime}\left(b_{i} e_{i 1}\right) b_{i}\right)^{2} \\
& +U^{\prime}\left(\left(b_{i} e_{i 2}-\frac{1}{2} e_{i 2}^{2}\right) p\left(b_{i} e_{i 1}\right)+B\right) p^{\prime \prime}\left(b_{i} e_{i 1}\right) b_{i}^{2}
\end{aligned}
$$

Clearly $F_{e_{i 1}}<0$ to satisfy second order conditions for max with respect to $e_{i 1}$ Then the sign of $e_{i 1}(B)$ is the sign of $F_{B}$ so that $e_{i 1}(B)<0$ if $U$ is concave. This leads to as to a first hypothesis based on our theoretical approach:

Hypothesis 1. Effort in the first period decreases with the amount of universal basic income $B$.

Now, to consider the effect of the probability of being replaced, $p\left(b_{i} e_{i 1}\right)$, suppose that $p\left(b_{i} e_{i 1}\right)$ depends parametrically on a parameter $q$. So we have $p\left(b_{i} e_{i 1}, q\right)$. Then the first order condition (Eq. 1) can be written compactly as

$$
F\left(e_{i 1}, B, q\right)=0
$$

so that

$$
\frac{\partial e_{i 1}(B, q)}{\partial q}=-\frac{F_{q}}{F_{e_{i 1}}}
$$

with

$$
\begin{aligned}
F_{q}=U^{\prime \prime} & \left(\left(b_{i} e_{i 2}-\frac{1}{2} e_{i 2}^{2}\right) p\left(b_{i} e_{i 1}, q\right)+B\right) p_{b e_{i 1}}\left(b_{i} e_{i 1}, q\right) p_{q}\left(b_{i} e_{i 1}, q\right) b_{i} \\
F_{e_{i 1}}= & U^{\prime \prime}\left(b_{i} e_{i 1}-\frac{1}{2} e_{i 1}^{2}\right)\left(b_{i}-e_{i 1}\right)^{2}-U^{\prime}\left(b_{i} e_{i 1}-\frac{1}{2} e_{i 1}^{2}\right) \\
& +U^{\prime \prime}\left(\left(b_{i} e_{i 2}-\frac{1}{2} e_{i 2}^{2}\right) p\left(b_{i} e_{i 1}, q\right)+B\right)\left(p_{b e_{i 1}}\left(b_{i} e_{i 1}, q\right) b_{i}\right)^{2} \\
& +U^{\prime}\left(\left(b_{i} e_{i 2}-\frac{1}{2} e_{i 2}^{2}\right) p\left(b_{i} e_{i 1}\right)+B\right) p_{\left(b e_{i 1}\right)^{2}}\left(b_{i} e_{i 1}, q\right) b_{i}^{2}
\end{aligned}
$$

Clearly $F_{e_{i 1}}<0$ to satisfy second order conditions for max with respect to $e_{i 1}$ Then the sign of $e_{i 1}(B)$ is the sign of $F_{q}$ so that $\frac{\partial e_{i 1}(B, q)}{\partial q}<0$ if $U$ is concave. This leads to our second hypothesis.

Hypothesis 2. Effort in the first period decreases with the probability of not being replaced. 
In summary, our theoretical framework suggests that basic income makes workers exert a lower amount of effort, and also that, when a tax makes her less likely to be replaced, she also decreases her effort level. We will turn to the comparison of these predictions, which on the other hand are quite reasonable in principle, with the results of the experiment.

\section{Results}

Our first result is that the threat of substitution by robots does not change the productivity of workers, in contradiction with hypothesis 2 . Figure 1 shows the production of the first phase for all participants in each of the 9 treatments. As can be seen from the graph, even if the dispersion varies across treatments, the means and medians are located almost perfectly on a horizontal, straight line. A $t$-test of difference in means also shows there are no statistical differences between the outputs of the first phase in the different treatments. In particular, there is no difference between the output in the first phase of the baseline treatment, when workers cannot be substituted by robots, and all the other treatments, when the substitution is possible. Hence, we conclude that there is no effect on effort on the threat of robot substitution. It is important to note for reference that the amount of points earned during this phase is approximately 17 points averaging over all treatments.

Looking now at the production in the second phase, depicted in Fig. 2, corresponding to those workers who were not substituted by robots, we observe an increase in the average output of $13.5 \%$ with respect to phase 1 , with the maximum growth taking place in the treatment without basic income or tax at $18.5 \%$, and the minimum growth, $9.5 \%$, for the exogenous treatment without basic income. The increase is quite homogeneous between treatments as can be seen from Fig. 2 .

Regarding the effects of universal basic income or taxes, from Fig. 1 we can conclude that the output in the first phase of those treatments is statistically the same as that observed in the baseline treatment. This implies that there is no disincentive to effort arising from either basic income or the tax on robots. This is in stark contrast with hypothesis 1 from the standard theoretical benchmark discussed in the previous section. As far as the universal basic income is concerned, further support comes when data are aggregated, as shown in Fig. 3, which compares the output of subjects in the first phase for treatments with and without basic income and suggests there are no differences. The $t$-test for differences in means again confirms there are no statistical differences in output between the two types of treatments. On the other hand, the bottom panel of Fig. 3 presents the production of participants in the first phase of endogenous treatment without basic income and without tax with the output of the first phase without basic income and with tax. The amount implemented as tax in the experiment was 3.4, to be compared with the average points earned in the baseline production phase of 17 . As with the basic universal income, there are no statistical differences between the output of subjects when there is a tax and when there is not. Indeed, Fig. 3 has the same shape as the previous one, showing the similarity between the treatments with and without taxes.

Another conclusion that arises from our experimental data is that a tax on the substitution of workers reduces the likelihood that workers are replaced. It has to be borne in mind that one of the policies that have been suggested in this situation of automation (Abbott and Bogenschneider, 2018; Guerreiro et al., 2017) consists precisely in the application of a tax when a human job is replaced by a robot. We measure the impact of the tax using a regression analysis. One of the variables is a dummy for the presence (or not) of a tax (variable TAXYes), whereas another is a dummy for the presence of basic income (variable RBYes), and finally we include a dummy for gender (variable SexMMale). The results from the logit regression are shown on Table 1. The negative sign of the variable TAXYes shows that the probability of replacement is lower when there is a tax. Another variable takes into account the difference in productivity between the robot and the human (variable I(ProdRob-Prod1)): its coefficient is positive, which means that the higher the productivity difference between robot and human, the higher the replacement probability. The ratio between the coefficients of the two variables is roughly 4.5 , indicating the productivity differential necessary to compensate a unit tax for the use of a robot. The 95\% confidence interval of the ratio of coefficients (found via bootstrapping) is $(1.06,8.18)$.

We have also considered the possibility that workers that have not being replaced by a robot because of a managerial decision increase their effort in return. There is a wide literature in anthropology, sociology and behavioral economics, (see, e.g.,

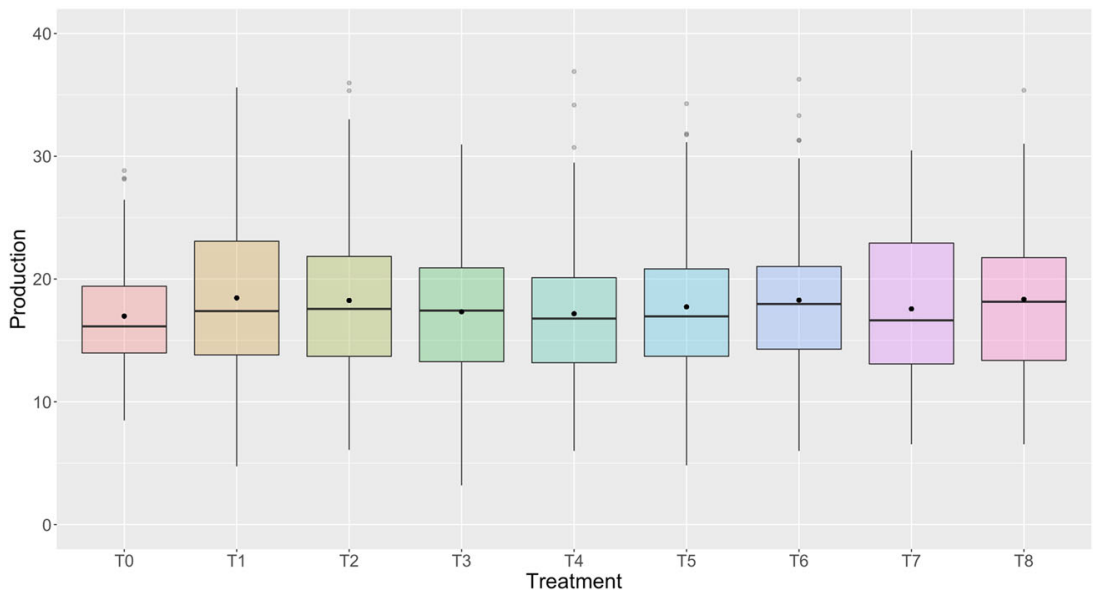

Fig. 1 First phase production by treatment. Production is computed as the number of earned points during the first phase of the experiment, and the horizontal axis indicates the different treatments carried out. Treatments are labeled as follows: T0, Baseline; T1, Endogenous without universal basic income and tax; T2, Endogenous M2 with universal basic income and without tax; T3, Endogenous M2 without universal basic income and with tax; T4, Endogenous M2 with universal basic income and tax; T5, Endogenous M3 without universal basic income and tax; T6, Endogenous M3 without universal basic income and with tax; T7, Exogenous without universal basic income, and T8, Exogenous with universal basic income. Boxes show the mean of the distribution as a dot and the median as a line, while the box itself indicates the second and third quartiles. Dots are outliers, defined as points beyond 1.5 the interquartile range, and whiskers show the range of points that are not outliers. 


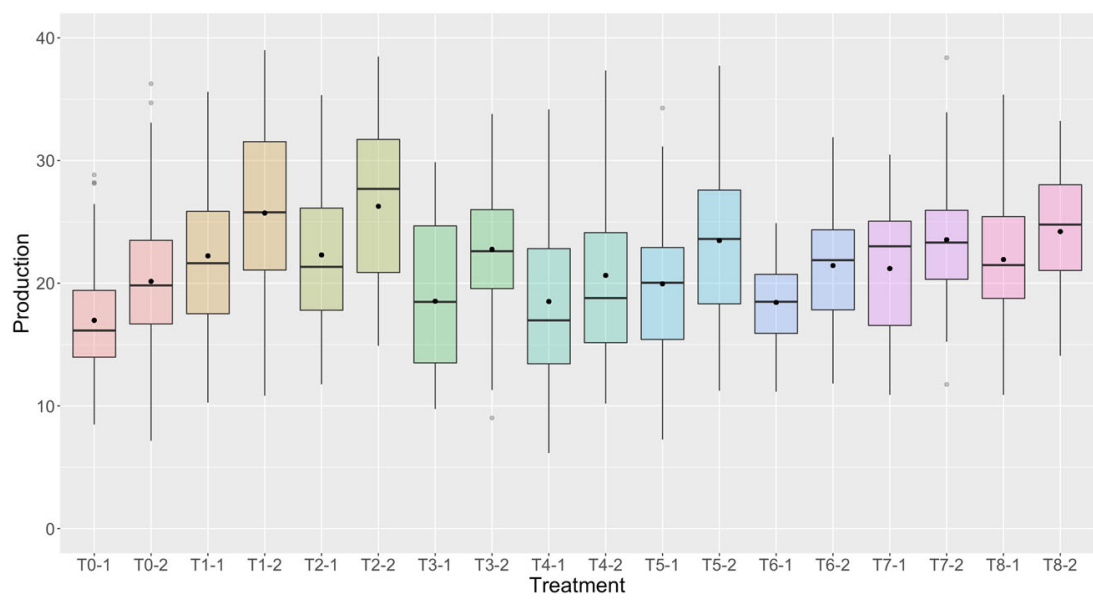

Fig. 2 Comparison of the production in the two phases by treatment. Production is computed as the number of earned points during the two phases of the experiment, and the horizontal axis indicates the different treatments carried out. Labels are as in Fig. 1, and the additional 1 or 2 refer to the first and the second parts of the experiment. Boxes are as in Fig. 1.

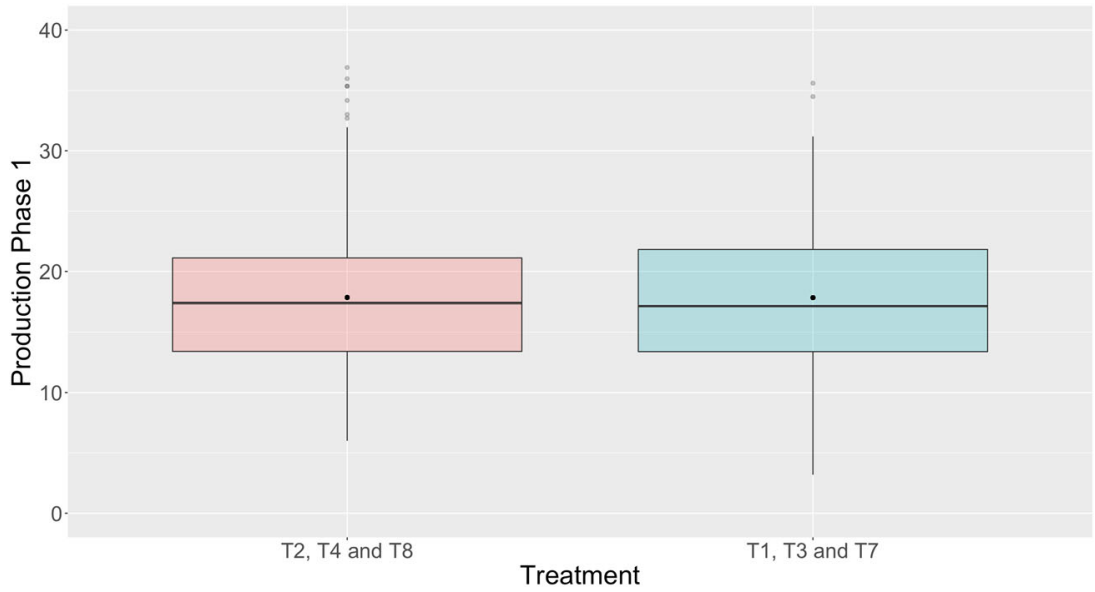

Fig. 3 Comparison of aggregated outputs in treatments with and without basic income or tax. Top: Output in the first phase for treatments with basic income and without basic income. Bottom: Output in the first phase of treatments with and without tax, when there is no basic income. Boxes and labels are as in Fig. 1.

\section{Table 1 Results from the logit model.}

\begin{tabular}{lclrl} 
& Estimate & Std error & $\boldsymbol{z}$ value & $\operatorname{Pr}(>|\mathbf{z}|)$ \\
\hline Intercept & -0.38940 & 0.29910 & -1.302 & 0.1929 \\
I(ProdRob-Prod1) & 0.14342 & 0.02095 & 6.846 & $7.58 \mathrm{e}-12^{\star \star \star}$ \\
TAXYes & -0.64306 & 0.31249 & -2.058 & $0.0396^{\star}$ \\
RBYes & 0.10227 & 0.30313 & 0.337 & 0.7358 \\
SexMMale & 0.29599 & 0.30890 & 0.958 & 0.3380 \\
\hline Significance: ${ }^{* \star *} 0,001 ;{ }^{* *} 0,01 ;{ }^{*} 0,05$. & & & \\
\hline
\end{tabular}

Cabrales and Ponti, 2015), suggesting that we may expect a beneficial act to be reciprocated. Thus, managers not replacing workers when the randomly assigned robot is more productive could be interpreted as one of those actions that deserve a reciprocation, and indeed, the worker can do so by making more effort. One would also expect this to happen only in endogenous treatments, as workers should not feel the need to reciprocate a decision made by machines. Figure 4 shows, however, that there are no significant differences in phase 2 for workers that are chosen not to be substituted in exogenous versus endogenous treatments. The $t$-test of equality in means accepts the null with a $p$-value of 0.6825 . This shows that workers do not reciprocate their managers when they have not been replaced by a robot.

A more detailed study of the individual behavior of type $A$ subjects, i.e., of managers does not reveal distinct patterns of behavior. Table 2 collects the rates of substitution for the different sub-cases of the endogenous treatment. One would expect that managers would replace the worker every time that the robot is more efficient, and never replace her otherwise. However, in some cases, reaching about $40 \%$ in the condition with tax, the manager does not do that, showing probably some concern for the welfare of the worker. The opposite situation is perhaps more puzzling. When the worker is more efficient, she is sometimes replaced, about $15 \%$ of the time, reaching an astonishing $30 \%$ when there is neither income nor tax. Another way of looking at these data is the plot in Fig. 5. As can be seen, in the positive side of the horizontal axis, corresponding to workers being more efficient that their candidate replacing robot, the pink column, representing no replacement, is dominant. On the negative side, when the robot is better than the workers, the bars are predominantly green, which indicates that the worker is replaced. Nevertheless, the pink bars are equally distributed for not so large negative differences. One would think the replacement is guided by a threshold strategy, but for this to be true, the pink bars on the 
negative side would have to be decreasing and even disappear as the difference becomes larger which is not the case until the difference becomes very large. Finally, as one can see in Fig. 5, the cases of part time or shared jobs (light blue) are scarce, and do not show any specific pattern.

\section{Discussion}

In this work, we report the results of an experiment designed to test the effect of the possibility of being replaced by a robot on the

\section{Table 2 Rates of substitution by robots.}

\begin{tabular}{|llllll|} 
& \multicolumn{2}{l}{ Lower } & \multicolumn{3}{l}{ Higher } \\
\cline { 2 - 3 } \cline { 6 - 6 } \cline { 5 - 6 } & Substituted & No & & Substituted & No \\
\hline No income no tax & $72.2 \%$ & $27.8 \%$ & & $29.2 \%$ & $70.8 \%$ \\
Income & $84.2 \%$ & $15.8 \%$ & & $9.1 \%$ & $90.9 \%$ \\
Tax & $59.6 \%$ & $40.4 \%$ & & $7.7 \%$ & $92.3 \%$ \\
Income and tax & $63.8 \%$ & $36.4 \%$ & & $15.4 \%$ & $84.6 \%$ \\
\hline
\end{tabular}

workers' productivity, and also to find out whether different policies are relevant in this area. We have found that workers do not produce more when they can be substituted by robots and that the two policies considered (universal basic income or tax on robots) do not affect the workers' productivity. Of these two policies, a tax levied on robots does reduce the probability of worker replacement, although the behavior of managers in our experiment is not easy to understand. Finally, the possibility of part-time jobs is practically never used in our setup.

Let us first discuss some of these results in light of our theoretical framework. Our first result runs contrary to our Hypothesis 2. It can nevertheless be accommodated in the framework. Note that the hypothesis 2 is a direct consequence of Eq. (5). But if one looks deeper into that equation, one can see (Eqs. (7) and (6)) that a low value of $U^{\prime \prime}($.$) with respect to U^{\prime}($.$) , that is a very$ concave utility (high risk aversion) would lead to a low enough response in effort that would not be picked up in the data. High levels of risk aversion are not uncommon in environments with high potential losses like the financial markets (Cohn et al., 2015) and in agricultural economies (Yesuf and Bluffstone, 2009). A similar thing occurs with our result that universal basic income

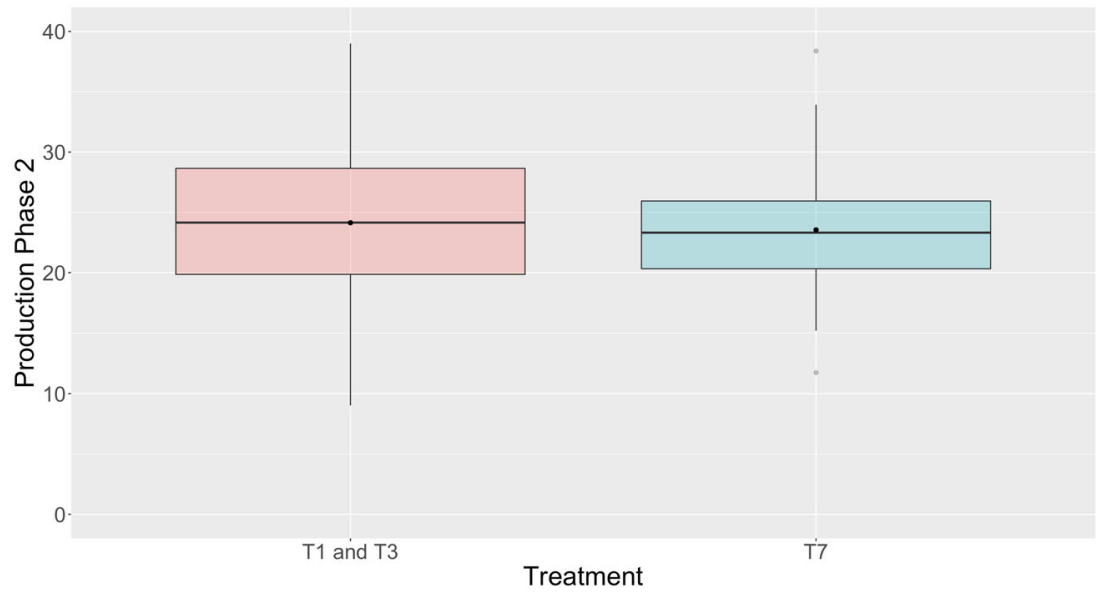

Fig. 4 Production does not increased in the second phase when workers are not substituted. Aggregate production in the second phase for endogenous treatments 8 without basic income, but with or without tax) compared to production in the second phase for the exogenous treatment, where decisions are taken exogenously. Boxes and labels are as in Fig. 1.

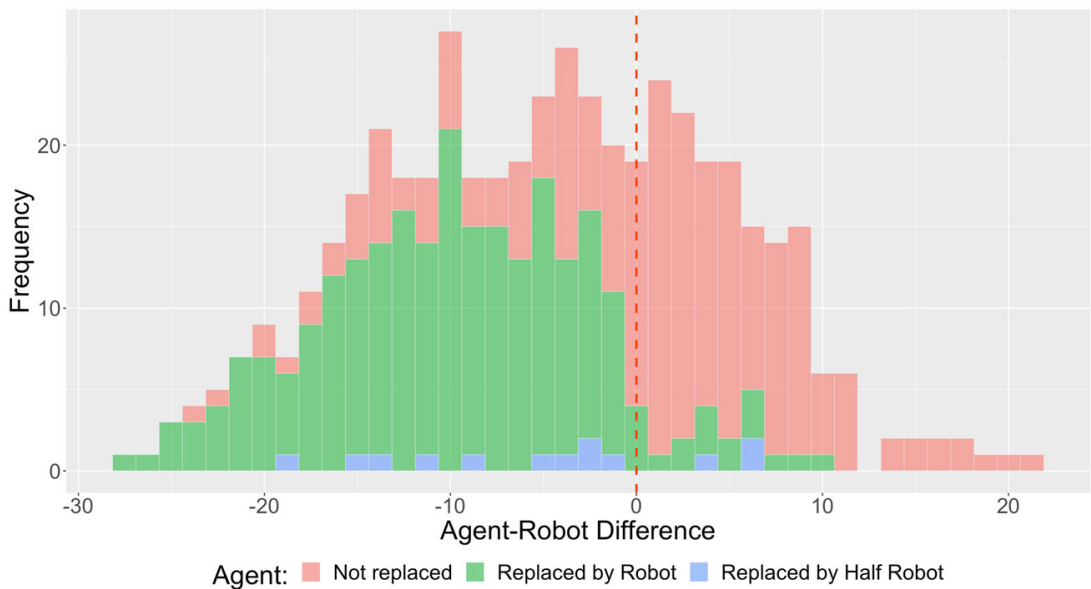

Fig. 5 Workers that were replaced, or not, by a robot, or half a robot as a function of the difference in production between the worker and the robot randomly assigned to replace her. Green, number of instances in which the worker was replaced. Pink, number of instances in which the worker was not replace. Blue, replacements keeping a part-time contract. 
does not decrease workers' effort. It is contrary to Hypothesis 1 , a consequence of Eq. (2). But from Eqs. (4) and (3) one can also see that high risk aversion can easily explain the apparent lack of response by the workers. Other mechanisms are indeed possible to explain those observations. A different model, where agents have multiple priors and maximin preferences as in (Gilboa and Schmeidler, 1989) and (Klibanoff et al., 2005) could also explain those results. Our experimental setup is not designed to test between these alternative theories, but we hope that our results will encourage future research in this direction.

Behavioral economics can explain why managers do not always automate when the robot is more productive, as the workers lose more than the managers gain. A simple expansion of our theoretical framework where agents have egalitarian (social) preferences as in (Cabrales and Ponti, 2015) would take account of this result. This could be exacerbated in our case, because the worker is substituted by a machine. This is important because the loss of a job is very important for personal identity issues (see, e.g., Schob, 2012).

It is also interesting to discuss another of our observations, namely the increase in production in the second phase with respect to the first one. Of course, a component of this is the contribution of more efficient robots, but as shown in Fig. 2, the production by human participants also increases. This result may arise for two reasons: It can be explained because of a learning effect of participants (even though the complexity of second period task was higher than the first) or because of a selection bias (the most productive workers are those that proceed to the second phase).

As far as the effect of the universal basic income or of taxes is concerned, we want to stress that our conclusions are drawn for specific values of those policies. In particular, we have only tested a basic income equivalent to one fifth of the output, so we cannot claim that a larger basic income would have no effect. More research would be needed to ascertain that effect. The effect of taxes is more likely to be representative of the general behavior, albeit it can also be expected that a very low tax may not be effective.

Also, we cannot discern with our experiment the impact of automation on employment. Our experiment confirms that not all jobs for which robots are more productive get replaced even in our case, where there is no issue of quality of work. In addition, we cannot take into account the impact of lower costs, and the higher sales, within other jobs in the same industry, or the general equilibrium effects. The literature we discuss in the introduction suggests that even if many jobs are replaced, the global effect on employment will be small or even positive.

We have discussed two policy instruments, "robot taxes" and universal basic income, to mitigate the effects of automation on employees whose skills are made redundant. Our conclusion is that taxes are effective to deter employers from automating some jobs, and universal basic income protects the income of workers without making them less productive. But both instruments have wider implications. Universal basic income is far costlier, as it affects (by definition) all citizens, and it requires significant increases in taxation to fund it (Hoynes and Rothstein, 2019). It is thus best seen as a policy in the context of the general fight against inequality, rather than something narrowly related to automation. On the other hand, "robot taxes" are targeted, and cheaper. They affect just the workers and firms involved in automation. But it also slows technical change, which can be a major problem for society in the long-run. Thus, they seem sensible only "while the current generations of routine workers, who can no longer move to non-routine occupations, are active in the labor force," as Guerreiro et al. (2017) show.

In conclusion, this work represents a first step in the exploration of human reaction to automation and in the study of policy decisions that can have an impact on the process. Our results suggest that the general worker population may not be well aware of the advancement of automation, and therefore more information should be provided so they can make decisions on their own careers within a proper context. Perhaps more importantly, it turns out that the universal basic income does not decrease productivity; if confirmed by future research, this points out to a means to alleviate the circumstances of workers affected by automation. On the other hand, this policy can coexist with a tax on robots that would have two benefits: reduce the substitution rate, and provide funds to support the universal basic income. All together, our results indicate that there is much room for action by policy makers to modulate the automation process and its negative consequences.

\section{Ethics statement}

This study has received approval from the ethics committee of Universitat de València, and the study was conducted following the approved guidelines.

\section{Data availability}

Data is available from the authors upon request.

Received: 24 June 2020; Accepted: 17 November 2020; Published online: 16 December 2020

\section{References}

Abbott R, Bogenschneider B (2018) Should robots pay taxes: tax policy in the age of automation. Harvard Law Policy Rev 12:145-175

Acemoglu D, Restrepo P (2017) Robots and Jobs: evidence from USLabor markets. J Pol Econ 128:2188-2244

Arntz M, Gregory T, Zierahn U (2016) The Risk of Automation forJobs in OECD countries. OECD Social, Employment and Migration Working Papers. https://doi.org/10.1787/1815199X Accessed 17 Nov 2020

Autor D, Salomons A (2018) Is automation labor-displacing? Productivity growth, employment, and the labor share. Brookings Paper Econ Activity 2018:1-87

Blake PR, McAuliffe K, Corbit J et al. (2015) The ontogeny of fairness in seven societies. Nature 528:258-261

Cabrales A, Ponti G (2015) Social preferences. In: Branas-Garza P, Cabrales A (eds) Experimental economics. Palgrave Macmillan, London, pp. 87-104

Cohn A, Engelmann J, Fehr E, Marechal MA (2015) Evidence for countercyclical risk aversion: an experiment withfinancial professionals. Am Econ Rev 105:860-885

Efron B, Tibshirani RJ (1993) An introduction to the bootstrap. Chapman \& Hall/ CRC, New York

Frank MR, Sun L, Cebrian M, Youn H, Rahwan I (2018) Smallcities face greater impact from automation. J R Soc Interface 15:20170946

Frey CB, Osborne MA (2013) The future of employment: how susceptible are jobs to computerisation? Oxford University Press, Oxford

Gilboa I, Schmeidler D (1989) Maxminexpected utility with non-unique prior. J Math Econ 18:141-153

Guerreiro J, Rebelo S, Teles P (2017) Should robots be taxed? Working paper no. w23806, National Bureau of Economic Research. https://www.nber.org/ papers/w23806 Accessed 17 Nov 2020

Hoynes H, Rothstein J (2019) Universalbasic income in the United States and advanced countries. Ann Rev Econ 11:929-958

Kangas O, Jauhiainen S, Simanainen M, Yliknn M (2019) The basic income experiment 2017-2018 in Finland: preliminary results. Ministry of Social Affairs and Health, Finland. https://apo.org.au/node/260496 Accessed 17 Nov 2020

Klibanoff P, Marinacci M, Sujoy M (2005) A smooth model of decision making under ambiguity. Econometrica 73:1849-1892

Levitt SD, List JA (2007) What do laboratory experiments measuring social preferences reveal about the real world? J Econ Perspec 21:153-174

Levitt SD, List JA, Sadoff SE (2011) Checkmate: exploringbackward induction among chess players. Am Econ Rev 101:975-990

Manyika, J, Lund, S, Chui, M et al. (2017) Jobs Lost, Jobs Gained: Workforcetransitions in a time of automation. McKinsey Global Institute. https:// www.mckinsey.com/featured-insights/future-of-work/jobs-lost-jobs-gained- 
what-the-future-of-work-will-mean-for-jobs-skills-and-wages Accessed 17 Nov 2020

Michaels G, Natraj A, VanReenen J (2014) Has ICT polarized skilldemand? Evidence from eleven countries over 25 countries. Rev Econ Stat 96:60-77

Noguera JA, DeWispelaere J (2006) A plea for the use oflaboratory experiments in basic income research. Basic Income Stud 1:2

Schöb R (2012) Unemployment and identity. CESifo Economic Stud 59:149-180

World Bank (2016) World Development Report 2016, Washington. https://www. worldbank.org/en/publication/wdr/wdr-archive. Accessed 17 Nov 2020

Yesuf M, Bluffstone RA (2009) Poverty,risk aversion, and path dependence in lowincome countries: experimentalevidence from Ethiopia. Am J Agric Econ 91:1022-1037

\section{Acknowledgements}

This research originates as a contribution to the goals of Fundacin COTEC on understanding and advancing innovation. We are grateful to COTEC, and in particular to Aleix Pons and Jorge Barrero, for discussions and support. Additional support from grant PGC2018-098186-B-I00 (BASIC) from Ministerio de Ciencia e Innovación/FEDER (Spain/UE) and from grants PRACTICO-CM and CAVTIONS-CM-UC3M from the Comunidad de Madrid and Universidad Carlos III de Madrid is gratefully acknowledged.

\section{Competing interests}

The authors declare no competing interests.

\section{Additional information}

Supplementary information is available for this paper at https://doi.org/10.1057/s41599020-00676-8.

Correspondence and requests for materials should be addressed to A.S.

Reprints and permission information is available at http://www.nature.com/reprints

Publisher's note Springer Nature remains neutral with regard to jurisdictional claims in published maps and institutional affiliations.

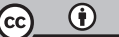

Open Access This article is licensed under a Creative Commons Attribution 4.0 International License, which permits use, sharing, adaptation, distribution and reproduction in any medium or format, as long as you give appropriate credit to the original author(s) and the source, provide a link to the Creative Commons license, and indicate if changes were made. The images or other third party material in this article are included in the article's Creative Commons license, unless indicated otherwise in a credit line to the material. If material is not included in the article's Creative Commons license and your intended use is not permitted by statutory regulation or exceeds the permitted use, you will need to obtain permission directly from the copyright holder. To view a copy of this license, visit http://creativecommons.org/ licenses/by/4.0/.

(C) The Author(s) 2020 